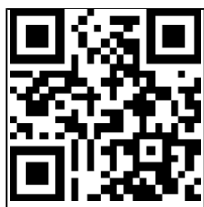

Editor's choice can to access mo free content

${ }^{1}$ Intermountain Healthcare, Salt Lake City, Utah, USA

${ }^{2}$ Department of Family Medicine, University of California Los Angeles, Los Angeles, California, USA ${ }^{3}$ Departments of Family Medicine and Orthopaedic Surgery, University of California Los Angeles, Los Angeles, California, USA

\section{Correspondence to}

Dr Elizabeth A Joy, Community Health, Intermountain Healthcare, $36 \mathrm{~S}$. State St. 8th Floor, Salt Lake City, UT 84111, USA; liz.joy@imail.org

Accepted 7 December 2015

\title{
2016 update on eating disorders in athletes: A comprehensive narrative review with a focus on clinical assessment and management
}

\author{
Elizabeth Joy, ${ }^{1}$ Andrea Kussman, ${ }^{2}$ Aurelia Nattiv ${ }^{3}$
}

\section{ABSTRACT}

Eating disorders, such as anorexia nervosa and bulimia nervosa, can have devastating effects on both the health and performance of athletes. Compared to non-athletes, both female and male athletes are at higher risk of developing an eating disorder. This is especially true for athletes participating in sports where low body weight or leanness confers a competitive advantage. Screening for disordered eating behaviours, eating disorders and for related health consequences should be a standard component of preparticipation examinations, and team physicians should be knowledgeable of the updated diagnostic criteria for eating disorders in the Diagnostic and Statistical Manual-V. Athletes with eating disorders should undergo thorough evaluation and treatment by an experienced multidisciplinary team. Team physicians play a critical role in decision-making on clearance for participation and return to play. Using evidence-based guidelines for clearance and return to play encourages transparency and accountability between the sports medicine care team and the athlete. Efforts to prevent eating disorders should be aimed at athletes, coaches, parents and athletic administrators, and focused on expanding knowledge of healthy nutrition in support of sport performance and health.

\section{INTRODUCTION}

Eating disorders can have devastating effects on athlete health and performance. Although females represent approximately 90\% of those who seek medical care for an eating disorder, males can be affected as well. ${ }^{1-3}$ Understanding the epidemiology and pathophysiology of eating disorders allows the sports medicine clinician to optimise his or her role in screening at-risk athletes and providing treatment. By intervening early and comprehensively, clinicians can decrease serious health and performance consequences.

\section{EPIDEMIOLOGY}

In the USA, it is estimated that 10 million women, and 1 million men will suffer from a clinically significant eating disorder in their lifetime. ${ }^{4} 5$ Given the secretive nature and denial surrounding eating disorders, these numbers likely grossly underrepresent the total disease burden in the US population. In a Finnish community study, approximately half of all individuals with anorexia nervosa had not yet been identified by the healthcare system. ${ }^{2}$ Worldwide, rates of eating disorders in Western societies parallel those in the USA, whereas in developing countries, the likelihood of disease is considerably less. ${ }^{1}{ }^{6-11}$ Among athletes, estimating the prevalence of eating disorders remains somewhat elusive.

Disordered eating is more prevalent among athletes than non-athletes, ${ }^{12}$ illustrating the relative importance of this problem in the athletic community. The majority of studies investigate the prevalence of eating disorders in female athletes. In a study of 522 elite female athletes and 448 nonathlete controls completing a disordered eating questionnaire, clinical examination and interview, ${ }^{13}$ $18 \%$ of athletes were diagnosed with an eating disorder compared to only $5 \%$ of non-athlete controls. In addition, athletes tended to under-report disordered eating symptoms on questionnaires compared to the control group. A similar but larger study including 1620 athletes and 1696 controls found similar results-20\% of female athletes met criteria for an eating disorder, compared to $9 \%$ of female controls. ${ }^{12}$

Even among female athletes the rates of eating disorder vary by sport and have generally been higher in sports with weight classes (such as rowing), aesthetic sports (such as gymnastics or figure skating) and sports where having a low body mass is seen as advantageous (such as cross-country or cycling). These conclusions were supported by Sundgot-Borgen's ${ }^{13}$ study that found rates of eating disorders in aesthetic sports and weight-dependent sports were $25 \%$, compared to $12 \%$ in other sports. In the 2004 study the prevalence of eating disorders in aesthetic sports was $42 \%$, in endurance sports it was $24 \%$, in technical sports it was $17 \%$ and in ballgame sports it was $16 \% .^{12}$ Similarly, in a 2015 study of 108 elite German athletes who were age-matched with 108 non-athlete controls, rates of eating disorders were $17 \%$ in aesthetic sports, $2 \%$ in ball sports and $2 \%$ in non-athletes. ${ }^{14}$

Additional studies suggest that the prevalence of disordered eating behaviours (such as binging, using saunas, taking laxatives or diuretics, self-inducing vomiting, etc) is higher in the college-aged population, even in the absence of a formal eating disorder diagnosis. ${ }^{15}$ Similar to the trend in eating disorder prevalence, athletes in lean sports exhibited more disordered eating behaviours than non-lean sport athletes. ${ }^{13}{ }^{16}$ Glazer $^{17}$ found that disordered eating scores on standardised questionnaires were higher in athletes than non-athletes, and highest in athletes within physique salient sports. An Australian study also found that disordered eating behaviours and body dissatisfaction were higher in lean sports, regardless of level of competition. ${ }^{18}$ In some studies as much as $70 \%$ of athletes in weight class sports 
were dieting or exhibiting abnormal eating behaviours to reduce their weight before competition. ${ }^{8}$

\section{Eating disorders in male athletes}

An increasingly large body of research also indicates that eating disorders and disordered eating are significant problems among

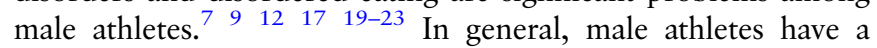
lower prevalence of eating disorders than female athletes, but a higher prevalence than male non-athletes. In one study, $20 \%$ of female athletes and $8 \%$ of male athletes met criteria for an eating disorder, compared to $9 \%$ of female controls and $0.5 \%$ of male controls. ${ }^{12}$ Another study of male and female rowers supported this trend by showing that male athletes had higher rates of pathological eating behaviours than the general male population-12\% of men had reported at least two binge eating episodes per week, $3 \%$ of men had self-induced vomiting and rates of rapid weight fluctuation and fasting were even higher in male athletes than female athletes $(57 \%$ vs $25 \%) .{ }^{23}$ Similar to the trend seen in elite female athletes, male athletes in lean sports are more likely to suffer from an eating disorder than those in other sports. In a 2004 study rates of eating disorders in male athletes in antigravitation sports were $22 \%$, as compared to $9 \%$ in endurance sports and $5 \%$ in ball game sports. ${ }^{12}$ In a study by Rosendahl, et $a l,{ }^{24}$ the prevalence of eating disorders among male athletes was $10 \%$ in endurance sports, $17 \%$ in weight class sports and $42 \%$ in antigravitation sports. As was observed in the female athlete population, numerous studies focusing specifically on male athletes in lean sports have found similarly high rates of disordered eating in this population, even in the absence of a formal eating disorder diagnosis. ${ }^{9} 17222526$ In a survey of 732 male collegiate athletes in the USA, Chatterton and Petrie ${ }^{22}$ found that male athletes who participated in weight class sports were more likely to engage in pathological eating and weight control behaviours and be symptomatic compared to male athletes in endurance sports or ball game athletes.

The importance of eating disorders in athletes is further emphasised by concerns that rates of eating disorders are increasing in the general population among individuals age 1519 years old. ${ }^{1}$ While this may be partially explained by changes to DSM-V criteria and greater awareness surrounding the Female Athlete Triad, it may also reflect broader cultural changes including public health efforts to reduce the burden of obesity.

\section{DIAGNOSTIC CRITERIA}

The majority of the studies mentioned above were conducted using definitions of eating disorders from the Diagnostic and Statistical Manual of Mental Disorders (DSM). The release of the DSM V has provided several important updates to the diagnostic criteria (tables 1-3). One study found that according to DSM IV criteria, $81 \%$ of adolescents and $75 \%$ of adults who presented for treatment of eating disorders were classified as 'eating disorder not otherwise specified' (EDNOS) because they did not meet all of the criteria for one type of eating disorder. ${ }^{27}$ The changes in the DSM V are intended to reduce the number of diagnoses which fall into the EDNOS category (or its renamed counterpart), which should facilitate more accurate descriptions of patient symptoms and also further research on eating disorders. Several studies have shown reductions in EDNOS diagnosis rates using the DSM V criteria. ${ }^{28} 29$

The criteria for anorexia nervosa have undergone the greatest number of revisions. Previously, individuals were required to have a weight less than $85 \%$ of normal. This has been updated to state that significantly low weight is 'less than minimally

Table 1 Presenting signs and symptoms ${ }^{50}$

\begin{tabular}{|c|c|c|}
\hline System & Signs and symptoms & \\
\hline General & $\begin{array}{l}\text { Marked or sudden weight loss, gain or fluctuation; } \\
\text { Failure to gain expected weight in child/adolescent } \\
\text { who is still growing and developing }\end{array}$ & $\begin{array}{l}\text { Hypothermia, cold intolerance } \\
\text { Fatigue }\end{array}$ \\
\hline Oral/dental and throat & $\begin{array}{l}\text { - Oral trauma/lacerations } \\
\text { Dental erosion or caries } \\
\text { - Perimolysis }\end{array}$ & $\begin{array}{l}\text { Parotid enlargement } \\
\text { Recurrent sore throats }\end{array}$ \\
\hline Gastrointestinal & $\begin{array}{l}\text { - Epigastric discomfort and/or abdominal pain } \\
\text { Early satiety and delayed gastric emptying } \\
\text { Gastroesophageal reflux } \\
\text { - Hematemesis }\end{array}$ & $\begin{array}{l}\text { Haemorrhoids, rectal fissures and rectal prolapse } \\
\text { Constipation } \\
\text { Diarrhoea }\end{array}$ \\
\hline Endocrine & $\begin{array}{l}\text { Irregular or missed menses } \\
\text { Loss of libido }\end{array}$ & Infertility \\
\hline Neuropsychiatric & $\begin{array}{l}\text { Memory loss/poor concentration } \\
\text { Insomnia } \\
\text { Depression, anxiety } \\
\text { - Obsessive compulsive behaviour }\end{array}$ & $\begin{array}{l}\text { Self-harm } \\
\text { Suicidal ideation/attempt } \\
\text { Seizures }\end{array}$ \\
\hline Cardiorespiratory & $\begin{array}{l}\text { Chest pain } \\
\text { Palpitations } \\
\text { Hypotension } \\
\text { - Bradycardia }\end{array}$ & $\begin{array}{l}\text { Other cardiac arrhythmias } \\
\text { Shortness of breath } \\
\text { Oedema }\end{array}$ \\
\hline Musculoskeletal & $\begin{array}{l}\text { Low bone mineral density } \\
\text { - Stress fractures }\end{array}$ & Fragility fractures \\
\hline Dermatological & $\begin{array}{l}\text { Lanugo hair } \\
\text { Hair loss } \\
\text { Yellowish skin discolouration } \\
\text { Calluses or scars on the dorsum of the hand (Russell's sign) }\end{array}$ & $\begin{array}{l}\text { Poor skin healing } \\
\text { Evidence of self-harm (superficial } \\
\text { I lacerations in various stages of healing) }\end{array}$ \\
\hline Genitourinary and renal & Electrolyte disturbances & Urinary abnormalities (both retention and f frequency) \\
\hline
\end{tabular}


Table 2 Eating behaviour questions ${ }^{50}$

\begin{tabular}{|c|c|}
\hline Topic & Questions \\
\hline $\begin{array}{l}\text { Questions to start the } \\
\text { conversation }\end{array}$ & $\begin{array}{l}\text { - How have you been feeling in general? How do you } \\
\text { feel about yourself? } \\
\text { Do you mind if we talk about your eating habits? }\end{array}$ \\
\hline Initial critical questions & $\begin{array}{l}\text { Are there foods or food groups that you avoid } \\
\text { eating? How do you feel about dieting in general? } \\
\text { How do you feel about your body size? } \\
\text { In what ways does your weight affect the way you } \\
\text { think about yourself? } \\
\text { What percentage of your waking hours do you } \\
\text { spend thinking about weight, food and body } \\
\text { image? }\end{array}$ \\
\hline Diet and dieting & $\begin{array}{l}\text { Do you worry that you have lost control of how } \\
\text { much you eat? } \\
\text { Are you happy with your eating behaviour? } \\
\text { Do you eat in secret? } \\
\text { What did you have for breakfast today/yesterday? } \\
\text { Lunch? Dinner? Snacks? } \\
\text { Do you count your calories? Watch fat grams? } \\
\text { Avoid certain foods? } \\
\text { Do you ever eat a lot in one sitting-enough that } \\
\text { you feel sick afterward? } \\
\text { Are you worried because sometimes you can't stop } \\
\text { eating? }\end{array}$ \\
\hline Vomiting/purging & $\begin{array}{l}\text { Do you make yourself throw-up because you feel } \\
\text { uncomfortably full? } \\
\text { Do you use diuretics, laxatives or diet pills? }\end{array}$ \\
\hline $\begin{array}{l}\text { Weight and } \\
\text { self-perception }\end{array}$ & $\begin{array}{l}\text { When you look in the mirror, what do you see? } \\
\text { What do you think you should weigh? What are } \\
\text { you doing to reach or maintain that weight? } \\
\text { Have you recently lost or gained a lot of weight in } \\
\text { a short period of time? } \\
\text { What was your lowest weight in the last year? Your } \\
\text { highest weight? }\end{array}$ \\
\hline Exercise and training & $\begin{array}{l}\text { Do you exercise above and beyond what is required } \\
\text { for your sport? } \\
\text { Do you feel anxious if you miss a workout? }\end{array}$ \\
\hline Family and support & $\begin{array}{l}\text { Does your family have any history of obesity, eating } \\
\text { disorders, depression, mental illness or substance } \\
\text { abuse (parents or other family members)? } \\
\text { Who are your primary sources of emotional } \\
\text { support? How do they support you? }\end{array}$ \\
\hline Health & $\begin{array}{l}\text { Female patients: When did you have your first } \\
\text { period? Are your periods regular? When was your } \\
\text { last period? } \\
\text { Do you have constipation? Diarrhoea? } \\
\text { Are you ever dizzy? Weak? Tired? Have you ever } \\
\text { fainted? } \\
\text { Do you get cold easily? } \\
\text { Have you lost any hair? Grown new hair? Do you } \\
\text { have dry skin? } \\
\text { Do you ever feel bloated? Have abdominal pain? } \\
\text { Do you have muscle cramps, bone pain? }\end{array}$ \\
\hline
\end{tabular}

Consider these questions for engaging patients and their family members in meaningful discussion that can help to identify the eating disorder. Reprinted with permission from Intermountain Healthcare.

normal weight in adults or less than expected weight in children and adolescents.' Additionally patients no longer need to explicitly endorse a fear of weight gain; this can now be inferred from patient behaviours. This change is likely to be particularly beneficial in the athlete population, because athletes may deny symptoms in an effort to continue competing. Lastly, amenorrhoea has been discarded as a diagnostic criterion for anorexia. Studies found that women who otherwise met criteria for anorexia but still had regular (or irregular) menses did not differ clinically from women with similar symptoms plus amenorrhoea. ${ }^{6}$ Removing amenorrhoea as a diagnostic requirement also facilitates the diagnosis of anorexia in men, postmenopausal women and adolescents with delayed menarche.

The new definition for bulimia nervosa in the DSM V reduced the required frequency of binge episodes and compensatory behaviours from twice per week to an average of once per week over a period of 3 months. This change was made because the frequency of binge episodes did not significantly impact prognosis or treatment, and it caused more EDNOS diagnoses. ${ }^{30}$ The DSM V also created a new diagnosis that had previously fallen under EDNOS—binge eating disorder. Lastly, the miscellaneous category previously called EDNOS has been changed to two categories-'other specified feeding or eating disorder,' and 'unspecified feeding or eating disorder.' The first of these categories is used for individuals who have a specific reason why they do not meet criteria for one of the types of eating disorder. For example, it would include a patient who had lost significant weight but was still within the normal weight range despite meeting all other criteria for anorexia. The second category is used in situations where the clinician cannot or does not clarify the reasons why the patient fails to meet full criteria for an eating disorder.

\section{COMMON COMORBIDITIES}

Individuals affected by eating disorders commonly suffer from other mental health conditions, including depression, anxiety, obsessive-compulsive disorder and substance use disorder. In a Canadian study almost half of all patients with eating problems were also found to have mood or anxiety disorders. ${ }^{31}$ Similarly, in a Swedish study half of patients with eating disorders had depression and one-quarter endorsed substance abuse. ${ }^{32}$ Lifetime prevalence of substance abuse in patients with bulimia nervosa is at least $30 \% .{ }^{10}$ Furthermore, among patients with bulimia nervosa, those with comorbid psychiatric conditions were more likely to report suicidal ideation and history of suicide attempts. ${ }^{33}$ Binge eating disorder has been found to significantly co-occur with depression, bipolar disorder, anxiety, bulimia nervosa, kleptomania and body dysmorphic disorder. ${ }^{34}$ Limited data exists regarding the relationship between eating disorders and comorbid mental health conditions in female and male athletes. A study in British athletes found a positive and significant relationship between eating psychopathology and risk of subsequent depressive symptoms 6 months later. ${ }^{35}$ Importantly, clinicians caring for an athlete with an eating disorder should consider and evaluate for other mental health conditions.

In addition to the aforementioned mental health conditions, premorbid medical conditions can increase the likelihood of subsequent eating disorders and contribute significantly to the morbidity of eating disorders. For example, individuals with type 1 diabetes mellitus are at higher risk for eating disorders later in life-in a German study, one in three females with type 1 diabetes and one in six males with type 1 diabetes had disordered eating and insulin restriction. ${ }^{36}$ Data on athletes with type 1 diabetes and eating disorders is unknown. Gastrointestinal conditions such as chronic constipation, gastroesophageal reflux disease (GERD), coeliac disease, lactose intolerance, delayed gastric emptying, gastroparesis and superior mesenteric artery syndrome may all occur as a result of eating disordered behaviour, $^{37-39}$ and in some cases may predate the eating disorder, thereby contributing to its onset. ${ }^{39}$

\section{CONSEQUENCES OF EATING DISORDERS}

There are both health and performance consequences of eating disorders. 
Table 3 Eating disorder laboratory evaluation and diagnostic testing ${ }^{50-52}$

\begin{tabular}{ll}
\hline Lab/test & When to use \\
\hline $\begin{array}{l}\text { Basic blood chemistry: serum electrolytes; renal function (BUN, Cr); calcium; liver } \\
\text { function tests; thyroid stimulating hormone (TSH); complete blood count (CBC), } \\
\text { differential and platelets; urinalysis }\end{array}$ & All patients with suspected eating disorders \\
$\begin{array}{l}\text { Additional blood chemistry: iron studies; vitamin D; vitamin B12; magnesium; } \\
\text { phosphorous }\end{array}$ & Malnourished and severely symptomatic patients \\
$\begin{array}{l}\text { Additional blood chemistry: serum luteinizing hormone; follicle stimulating } \\
\text { hormone; prolactin; estradiol; thyroid stimulating hormone (TSH)—if not previously } \\
\text { obtained; urine pregnancy test }\end{array}$ & Pabsence/delay of secondary sexual characteristics by age 13; \\
$\begin{array}{l}\text { Toxicology screen } \\
\text { Radiological imaging: dual energy X-ray absorptiometry (DXA), }\end{array}$ & Pecondary amenorrhea (no menses for three consecutive months) \\
radiographs, advanced imaging & DXA for patients with amenorrhoea for 6 months or more of prolonged \\
& oligomenorrhoea (<6 periods in 24 months); \\
ECG & Radiographs to evaluate for stress fractures, or more advanced imaging if needed \\
& Patients with syncope, recurrent near syncope, palpitations, resting supine heart rate \\
$<50$ bpm & Rapid weight loss; weight $<80 \%$ of ideal body weight \\
& Hypophophatemia
\end{tabular}

All patients with suspected or confirmed eating disorders should undergo laboratory testing as indicated. Additional testing should be performed based on presenting signs and symptoms. Reprinted with permission from Intermountain Healthcare.

\section{Health consequences}

Eating disorders have wide-ranging health consequences, including one of the highest mortality rates of any mental health condition. ${ }^{103740}$ Risk of premature death is 6-12 times higher in women with anorexia nervosa. ${ }^{41}$ Crude mortality rate is approximately $5 \%$ per decade. ${ }^{10}$ In 1994 the death of US gymnast Christy Henrich from anorexia nervosa was a devastating example of the extent to which athletes will manipulate their dietary intake and exercise to achieve what is perceived as an ideal body image. Death is most often caused by suicide or cardiac arrhythmia-suicide accounts for $20 \%$ of deaths among patients with anorexia nervosa, and $23 \%$ of deaths among patients with bulimia nervosa. ${ }^{42}{ }^{43}$ Particularly worrisome is the finding that among individuals with an eating disorder, overexercise (common among competitive athletes) is the disordered eating behaviour which is most strongly associated with suicidal behaviour. ${ }^{44}$ Death from cardiac arrhythmia may result from electrolyte disturbances associated with self-induced vomiting, laxative abuse and diuretic use, especially among those with extremely low body weight. While cardiac consequences of eating disorders-especially anorexia nervosa-are considered a significant contributor to morbidity and mortality, ${ }^{45}$ a recent meta-analysis of mortality rates in anorexia nervosa was unable to elucidate exact cause of death, aside from medical causes versus suicide. $^{46}$

Disordered eating behaviours such as restricted dietary intake, excessive exercise, binge eating, self-induced vomiting, laxative abuse, diuretic use, regurgitation and eat and spit, can affect nearly every system of the human body. While some individuals practice a single behaviour such as restriction, studies suggest that up to a third of individuals engage in two or more pathogenic behaviours. ${ }^{47}$ Furthermore, individuals who report using multiple compensatory behaviours have more severe presentations of eating disorders, lower levels of functioning and increased rates of general psychopathology. ${ }^{48}$ As athletes may approach the medical care team for evaluation of an 'eating disorder consequence' rather than seeking care directly for an eating disorder, sports medicine clinicians should be aware of the signs and symptoms of restricting and purging behaviours ${ }^{49}$ (table 1).

Among female athletes with eating disorders, especially those with restricted dietary intake, a commonly recognised consequence is the Female Athlete Triad. The Triad describes three distinct but inter-related conditions including low energy availability, menstrual dysfunction and low bone mineral density. $^{49} 5152$ Low energy availability (whether inadvertent, intentional or psychopathological), can result from low energy intake relative to high energy expenditure during training and is the underlying factor contributing to negative effects on reproductive and skeletal health. ${ }^{51} 52$

While not as extensively studied, there is increasing research on the health consequences of disordered eating in the male athlete. In a subset of male athletes, especially those participating in sports emphasising leanness, parallels to the Triad have been described ${ }^{53}$ that include low energy availability (with or without disordered eating) ${ }^{7} \quad 9 \quad 12 \quad 16 \quad 19-23$ (hypogonadotropic hypogonadism or other gonadal steroid effects ${ }^{54-58}$ ) and low bone mineral density. ${ }^{59-66}$ Similar to the female athlete, male athletes with low energy availability (with or without disordered eating) may be predisposed to stress fractures and bone stress injuries. ${ }^{61} 66$ However, our current understanding of the mechanisms of nutrition and low energy availability on neuroendocrine function and bone health in males is limited compared to that for female athletes and further research is needed.

\section{Performance consequences}

Athletic performance suffers as a result of eating disorders. ${ }^{67}$ Female athletes with anorexia nervosa and a body mass index $(\mathrm{BMI})<16.5$, and those with bulimia nervosa purging four or more times per day should be categorically restricted from participation in sport. ${ }^{51}$ Additionally, low energy availability leading to the loss of fat and lean body mass, electrolyte abnormalities and dehydration all contribute to poor sport performance. ${ }^{67}$ A study of junior elite female swimmers, found that those with energy restriction and ovarian suppression had poor sport performance compared to cyclic swimmers. ${ }^{68}$ Even among high school athletes, those with disordered eating behaviours were more than twice as likely to sustain a musculoskeletal injury during their competitive season. ${ }^{69}$

\section{SCREENING FOR EATING DISORDERS IN ATHLETES}

Several US sports medicine professional organisations (including the American Medical Society for Sports Medicine (AMSSM) and the American College of Sports Medicine (ACSM) have 
Box 1 Recommended screening questions for the female athlete triad ${ }^{51}$

Recommended questions:

1. Have you ever had a menstrual period?

2. How old were you when you had your first menstrual period?

3. When was your most recent menstrual period?

4. How many periods have you had in the past 12 months?

5. Are you presently taking any female hormones (oestrogen, progesterone, birth control pills)?

6. Do you worry about your weight?

7. Are you trying to or has anyone recommended that you gain or lose weight?

8. Are you on a special diet or do you avoid certain types of foods or food groups?

9. Have you ever had an eating disorder?

10. Have you ever had a stress fracture?

11. Have you ever been told you have low bone density (osteopenia or osteoporosis)?

These questions should be included as a part of the preparticipation physical examination (PPE).

Reprinted with permission from BJSM.

collaborated to develop the Preparticipation Physical Examination (PPE) monograph. ${ }^{70}$ Now in its fourth edition, the PPE includes several questions aimed at identification of disordered eating behaviours:

1. Do you worry about your weight?

2. Are you trying to, or has anyone recommended that you gain or lose weight?

3. Are you on a special diet or do you avoid certain types of food?

4. Have you ever had an eating disorder?

5. Have you ever taken any supplements to help you gain or lose weight or improve your performance?

Additional questions on the PPE questionnaire screen for downstream consequences of eating disorders including menstrual dysfunction (in female athletes), and stress fractures, mood disturbance and substance use (in female and male athletes). ${ }^{70}$ Clinicians should maintain a high index of suspicion for disordered eating since some studies show that athletes tend to under-report disordered eating behaviours on questionnaires. ${ }^{13}$

The Female Athlete Triad Coalition has published an 11-question screening tool (box 1) that aims to identify disordered eating, menstrual dysfunction and low bone mineral density. ${ }^{51}$ It is recommended that these questions be administered to athletes during the preparticipation examination.

\section{DIAGNOSIS AND EVALUATION OF ATHLETES WITH EATING DISORDERS}

Sports medicine providers serve an important role in evaluating disordered eating and diagnosing eating disorders. Physicians, athletic trainers, sport psychologists, sport dietitians and physical therapists interact with athletes and active persons, and may have an opportunity to identify eating disordered behaviours. Early identification and early intervention are associated with better outcomes. ${ }^{39}$ Referral of an athlete suspected of engaging in unhealthy eating behaviours to a physician with expertise in the evaluation and management of eating disorders, and especially with additional knowledge regarding the interaction with competitive sport, is a key first step. As is often the case in medicine, 'the mystery is in the history,' and given the secretive nature of eating disorders, this adage is particularly applicable when caring for athletes with eating disorders. Questions such as, 'what percentage of your waking hours do you spend thinking about food, weight and body image?' and 'in what ways does your weight affect the way you think about yourself?' are but a few questions that often open up a dialogue about feelings, eating behaviours and health consequences. A more complete list of questions to consider integrating into the medical history when evaluating an athlete suspected of having disordered eating or an eating disorder can be found in table 2 .

A review of systems and a comprehensive physical examination (table 1) can further aid in the identification of disordered eating behaviours and health consequences, leading to diagnosis as well as subsequent treatment. Laboratory evaluation and additional diagnostic testing are often required to better assess health consequences. Both historical and physical examination findings should guide the laboratory and additional diagnostic evaluation $^{352}$ (table 3). Female athletes who develop menstrual dysfunction and/or evidence of low bone mineral density-the Female Athlete Triad-should undergo testing of their reproductive hormones and evaluation of their bone mineral density as defined in the 2014 Female Athlete Triad Coalition Consensus Statement on Treatment and Return to Play of the Female Athlete Triad. ${ }^{51}$

\section{TREATMENT OF DISORDERED EATING AND EATING DISORDERS IN ATHLETES}

Once a diagnosis of disordered eating or an eating disorder has been made, a knowledgeable and experienced multidisciplinary team of healthcare professionals should care for the athlete, with a goal of personalised patient-centered care (figure 1). The first step in treatment is determining the level of care. Can the athlete be treated in an outpatient setting, or does he or she require a higher level of care in the hospital or in a residential treatment setting? Deteriorating physical and/or mental health are the primary reasons prompting a higher level of care-examples include rapid uncontrolled weight loss, severe electrolyte abnormalities, syncope, suicidal intent and inability to function in one's environment. The majority of individuals can be treated in an outpatient setting using the multidisciplinary team care model. In the athletic setting the team often consists of a physician, a sports dietitian, a mental health professional and the

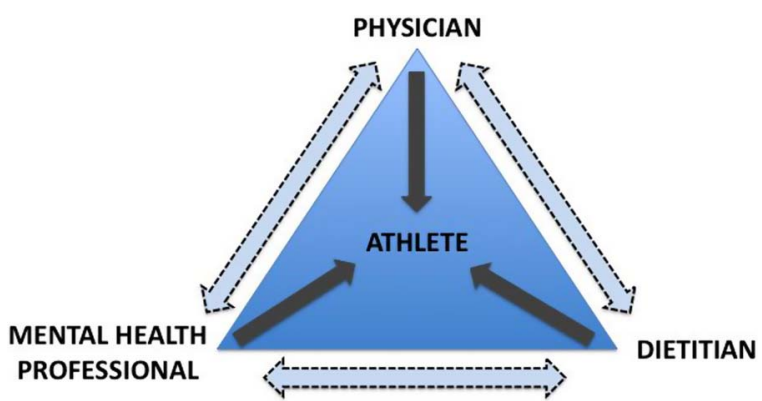

Figure 1 Multidisciplinary care. ${ }^{67}$ Multidisciplinary care of patients affected by eating disorders should include a physician, dietitian and mental health professional. Regular communication between team members facilitates clinically relevant information exchange, and cohesive, comprehensive, patient-centered care. Reprinted with permission from Intermountain Healthcare. 
athletic trainer. Communication among team members is critically important. The individual affected by the eating disorder must feel like he or she is receiving a cohesive and consistent message from the treatment team. While each member of the team plays a unique role in supporting the athlete's recovery from the eating disorder, there is considerable crossover in the care that team members provide-with the physician talking about nutrition, or the dietitian discussing feelings and function alongside calories and carbohydrates. Setting aside time for the team to 'round' and share important information about the athlete can help to facilitate care. Additional health professionals may have a consulting role in the care of the athlete affected by an eating disorder (such as psychiatry, or gastroenterology).

For younger athletes still living at home, engagement and alignment with parents or guardians is critically important. Knowing that chaotic or disruptive family situations (such as divorcing parents) can contribute to the development of an eating disorder, it is imperative that the multidisciplinary treatment team understands the environment in which the athlete lives, and takes that into account when developing and implementing treatment plans. ${ }^{39}$

The primary role of the physician is to address the eating disordered behaviours and their health consequences, and to support and reinforce the treatment plans of the dietitian, mental health professional and others involved in the athlete's care. Healthcare visits are typically monthly, although may be more or less frequent depending on the athlete's stage of recovery. Medical care should focus on the following areas:

- Function-Assessing day-to-day functioning

- How have you been doing since your last visit?

- Is there a time of day that your behaviours are better or worse?

- What helps you succeed (with changing behaviours, with treatment, etc)?

- Are you taking your medications as prescribed?

- Additional questions to develop rapport and further assess patient functioning (eg, 'How is school? Practice? Work? Family/Friends?').

- Physical health discussion-Discussing health-related topics, such as:

- A targeted symptom review: sleep, bowel habits, energy, urination, palpitations, syncope/near-syncope, menstruation, other issues or concerns

- Eating behaviours - restriction, binging, purging, etc

- Exercise and training behaviours - healthy and unhealthy; issues related to clearance and return to play

- Mental status-Assessing the patient's mental health with a standard mental status examination (MSE) and discussion of various topics, such as body image, stressors, and mental health issues.

- Physical health examination-Checking and recording the following:

- Vital signs-blinded weight, height, BMI, blood pressure, heart rate, temperature

- Change in weight since last visit

- Physical examination if necessary - throat, heart, lungs, extremities, etc

- Repeated tests/examination items from diagnosis as necessary

- Medications-Prescribing and managing medications as needed.

- Other health needs as necessary - Reviewing menstrual function, digestive issues, bone health, endocrinology manifestations, etc.

\section{Medication use}

Medications are often prescribed to patients with eating disorders to treat comorbid conditions such as depression and anxiety, or to manage physical complications. Target symptoms should be established with the patient and regularly monitored. Only two psychotropic medications have US Food and Drug Administration approval for the direct treatment of eating disorders-fluoxetine for use in patients with bulimia nervosa ${ }^{39} 71$ and lisdexamfetamine for use in patients with binge eating disorder. $^{72}{ }^{73}$ However, there is considerable off-label use of psychotropic medications ranging from antidepressants, ${ }^{39} 7174$ anxiolytics, ${ }^{74}$ antipsychotics ${ }^{75}$ and antiepileptics ${ }^{74}$ in an effort to curb eating disorder behaviours and treat comorbid symptoms of depression and anxiety, obsessive compulsive behaviours, thought disorder and sleep disturbance. Despite the use of these medications, there is limited evidence that use of psychotropic medications in the treatment of eating disorders is associated with improved clinical outcomes. ${ }^{76}$ It is also worth noting that the majority of the studies looking at treatment protocols for eating disorders do not distinguish between male and female patients, so it is unclear whether optimal treatment strategies differ by sex. ${ }^{17}$ Physicians should carefully consider the potential risks and benefits in prescribing psychotropic medications.

Patients may also benefit from additional medications, vitamins and supplements to treat health consequences of eating disordered behaviours. ${ }^{51} 77$ This includes the use of potassium replacement for hypokalaemia resulting from self-induced vomiting; hormone therapy for female patients with clinical indications for replacement, ${ }^{51}$ and medications aimed at addressing impaired gastrointestinal motility. ${ }^{77}$

Sports medicine physicians should be aware of the unique interaction between medications and sport participation. For example, medications that induce orthostatic hypotension should not be prescribed to a gymnast who experiences many changes in posture and position. Likewise, sedating medications may not be tolerated by student athletes attending school, practice or trying to complete evening homework tasks.

\section{CLEARANCE AND RETURN TO PLAY CONSIDERATIONS}

One of the most important areas of concern for the team physician involves the decision-making process regarding clearance and return to play. For female athletes with disordered eating behaviours and health consequences related to those behaviours, the Female Athlete Triad: Cumulative Risk Assessment in the 2014 Female Athlete Triad Coalition Consensus Statement on Treatment and Return to Play of the Female Athlete Triad can serve as a guide to physicians making clearance and return to play decisions (table 4). ${ }^{51}$ The risk assessment tool takes into account: dietary restriction, BMI, menstrual history (delayed menarche, oligomenorrhoea, amenorrhoea), bone mineral density and history of stress reaction or fracture. Each risk factor carries a point value, and the numeric score suggests whether an athlete should receive full clearance, provisional/limited clearance or restriction from participation (see table 5). ${ }^{51}$ While this risk assessment tool can help to guide clearance and return to play decisions for athletes with disordered eating and eating disorders, physicians should combine these recommendations with their own clinical decisionmaking skills, and need not use the tool in isolation. Of note, athletes diagnosed with anorexia nervosa who have a BMI $<16 \mathrm{~kg} / \mathrm{m}^{2}$ or athletes with moderate-to-severe bulimia nervosa (purging $>4$ times/week) should be categorically restricted from training and competition. Female athletes who fall into moderate and high- risk categories should have a written contract completed 
Table 4 Female athlete triad cumulative risk assessment ${ }^{51}$

\begin{tabular}{|c|c|c|c|}
\hline \multicolumn{4}{|l|}{ Magnitude of risk } \\
\hline Risk factors & Low risk $=0$ points each & Moderate risk=1 point each & High risk=2 points each \\
\hline Low EA with or without DE/ED & $\square$ No dietary restriction & $\begin{array}{l}\square \text { Some dietary restriction*; } \\
\text { Current or history of DE }\end{array}$ & $\square$ Meets DSM V criteria for ED $\dagger$ \\
\hline Low BMI & $\begin{array}{l}\square \mathrm{BMI} \geq 18.5 \mathrm{~kg} / \mathrm{m}^{2} \text { or } \\
\geq 90 \% \mathrm{EW} \neq \text { or } \\
\text { weight stable }\end{array}$ & $\begin{array}{l}\square \text { BMI } 17.5<18.5 \mathrm{~kg} / \mathrm{m}^{2} \text { or } \\
<90 \% \text { EW or } \\
5 \text { to }<10 \% \text { weight loss/month }\end{array}$ & $\begin{array}{l}\square \mathrm{BMI} \leq 17.5 \mathrm{~kg} / \mathrm{m}^{2} \text { or } \\
<85 \% \text { EW or } \\
\geq 10 \% \text { weight loss/month }\end{array}$ \\
\hline Delayed menarche & $\square$ Menarche $<15$ years & $\square$ Menarche 15 to $<16$ years & $\square$ Menarche $\geq 16$ years \\
\hline Oligomenorrhoea and/or amenorrhoea & $\square>9$ menses in 12 monthst & $\square$ 6-9 menses in 12 monthst & $\square<6$ menses in 12 monthst \\
\hline Low BMD & $\square$ Z-score $\geq-1.0$ & $\square$ Z-score $-1.0 \S<-2.0$ & $\square$ Z-score $\leq-2.0$ \\
\hline Stress reaction/fracture & $\square$ None & $\square 1$ & $\square \geq 2 ; \geq 1$ high risk or of trabecular bone sites 9 \\
\hline $\begin{array}{l}\text { Cumulative risk (total each column, then add for } \\
\text { total score) }\end{array}$ & points + & points + & _ points $=\ldots$ Total Score \\
\hline \multicolumn{4}{|c|}{$\begin{array}{l}\text { The cumulative risk assessment provides an objective method of determining an athlete's risk using risk stratification and evidence-based risk factors for the Female Athlete Triad. This } \\
\text { assessment is then used in conjunction with the physician's clinical decision-making skills to determine an athlete's clearance for sport participation (table 10). } \\
\text { Reprinted with permission from BJSM. } \\
\text { *Some dietary restriction as evidenced by self-report or low/inadequate energy intake on diet logs. } \\
\text { tCurrent or history of disordered eating. } \\
\text { ¥Absolute BMI cut-offs should not be used for adolescents. } \\
\text { §Weightbearing sport. } \\
\text { १High-risk skeletal sites associated with low BMD and delay in return to play in athletes with one or more components of the triad include stress reaction/fracture of trabecular sites } \\
\text { (femoral neck, sacrum, pelvis). } \\
\text { BMD, bone mineral density; BMI, body mass index; DE, disordered eating; EA, energy availability; ED, eating disorder; EW, expected weight. }\end{array}$} \\
\hline
\end{tabular}

and signed by the athlete and each member of the multidisciplinary team. ${ }^{51}$ (figure 2).

While a similar evidence-based scoring system with concomitant clearance recommendations has not yet been developed for male athletes, the IOC has proposed a return to play model based on a red light (high risk), yellow light (moderate risk), green light (low risk) system. ${ }^{78}$

\section{PREVENTION}

Efforts to prevent disordered eating behaviour among athletes should be aimed at athletes, coaches, athletic administrators and parents. Primary prevention efforts work to expand athlete knowledge about healthy eating, pathological eating behaviours and their consequences, and what to do if you or a teammate are thought to have an eating disorder. ${ }^{52}{ }^{79}$ Athletes should be educated that dietary restriction and/or purging behaviour in pursuit of optimal weight and body composition will negatively impact sport performance and result in adverse health consequences. In one study, a peer-led educational programme for athletes resulted in improved bulimic pathology even 1 year after the intervention, and researchers noted an increase in the number of athletes who sought medical care because they had become concerned that they might have symptoms of the Female Athlete Triad. $^{80}$ Likewise, athletes, coaches and parents should be informed that the loss of menstruation is not a positive adaptation to high-intensity training and sport participation, and represents a state of low energy availability stemming from either intentional or unintentional dietary restriction. ${ }^{51}$ Studies have shown that educational programmes directed at coaches are successful in increasing their knowledge about eating disorders in athletes, including recognition and management. ${ }^{81}$ However, it is not yet clear whether this increased awareness translates to improved outcomes among athletes.

The National Collegiate Athletic Association (NCAA) has developed educational materials for coaches, athletic administrators and athletes in an effort to prevent eating disorders. ${ }^{82}$ They identify 10 strategies for coaches and administrators, which aim to reduce the likelihood of disordered eating and eating disorders among their athletes: ${ }^{83}$

1. Be aware of the symptoms of disordered eating.

2. Consult a registered dietitian who specialises in sport, particularly a Board Certified Specialist in Sports Dietetics (CSSD) to prescribe appropriate nutrition for optimal sport performance.

Table 5 Female athlete triad: clearance and return-to-play guidelines by medical risk stratification ${ }^{51}$

\begin{tabular}{|c|c|c|c|c|}
\hline & Cumulative risk score* & Low risk & Moderate risk & High risk \\
\hline Full clearance & 0-1 point & $\square$ & & \\
\hline Provisional/limited clearance & $2-5$ points & & $\begin{array}{l}\square \text { Provisional clearance } \\
\square \text { Limited clearance }\end{array}$ & \\
\hline Restricted from training and competition & $\geq 6$ points & & & $\begin{array}{l}\square \text { Restricted from training and competition-provisional } \\
\square \text { Disqualified }\end{array}$ \\
\hline
\end{tabular}

Reprinted with permission from BJSM.

${ }^{*}$ Cumulative risk score determined by summing the score of each risk factor (low, moderate, high risk) from the cumulative risk assessment (table 5). Clearance/RTP status for athletes moderate-to-high risk for the triad: provisional clearance/RTP_clearance determined from risk stratification at time of evaluation (with possibility for status to change over time depending on athlete's clinical progress); limited clearance/RTP-clearance/RTP granted, but with modification in training as specified by physician (with possibility for status to change depending on clinical progress and new information gathered); restricted from training/competition (provisional) — athlete not cleared or able to RTP at present time, with clearance status re-evaluated by physician and multidisciplinary team with clinical progress; disqualified-not safe to participate at present time. Clearance status to be determined at future date depending on clinical progress, if appropriate. Athletes diagnosed with anorexia nervosa who have a body mass index (BMI) $<16 \mathrm{~kg} / \mathrm{m}^{2}$ or with moderate-to-severe bulimia nervosa (purging $>4$ times/week) should be categorically restricted from training and competition. Future participation is dependent on treatment of their eating disorder, including ascertainment of $\mathrm{BMI}>18.5 \mathrm{~kg} / \mathrm{m}^{2}$, cessation of bingeing and purging and close interval follow-up with the multidisciplinary team. 
(Athlete Name)

The following items are mandatory and must be completed as prescribed. Failure to do so will result in the consequences listed below the requirements. All benefits and consequences are subject to change at any time and at the discretion of the Multidisciplinary Team. Multidisciplinary Team:

(Physician), (Psychotherapist), (Dietitian)

\section{Requirements:}

$\square$ Meet with

(therapist) $1 x$ per week, or as recommended by therapist.

$\square$ Meet with (dietitian) $1 x$ per week, or as recommended by dietitian.

$\square$ Meet with Dr. 1-2x per month, or as recommended by $\mathrm{Dr}$.

$\square$ Follow daily meal plan set forth by sports dietitian.

$\square$ Keep daily workout log updated with specific type, length, and effort.

$\square$ Weight gain of Ibs per week.

$\square$ Weekly weigh-in with

(name team member), or at time intervals of weeks.

$\square$ Must achieve minimal acceptable body weight of Ibs by (date).

$\square$ After this date, must maintain weight at or above minimal acceptable body weight.

$\square$ Limit of _ workout sessions per week with no one session being more than minutes in length.

All activity counts (e.g., biking, running, weight lifting, and swimming).

\section{Benefits:}

If $A L L$ requirements are met then clearance to participate in team activities and use of athletic facilities will: $\square$ be granted $\square$ continue.

\section{Consequences:}

If ANY requirement(s) are not met then clearance to participate in team activities and use of athletic facilities will be revoked, and re-instatement will be at the discretion of the team physician and multidisciplinary team

I, have read this contract and all of my questions were answered.

\begin{tabular}{|c|c|c|}
\hline Athlete Name & Athlete Signature & Date \\
\hline Team Physician Name & Team Physician Signature & Date \\
\hline
\end{tabular}

Reprinted with permission from the British Journal of Sports Medicine, 2014

Figure 2 Treatment contract. ${ }^{51}$ A treatment contract should be considered for any patient who falls into the moderate or high-risk category. The contract specifies the criteria necessary to participate or return to sport. The contract should be signed by the athlete and team physician. Reprinted with permission from BJSM.

3. De-emphasise weight: Be aware of how you are communicating to athletes about weight and performance. Focus on ways for athletes to enhance their performance that do not involve weight.

4. Keep an open dialogue with athletes about the importance of nutrition and staying injury-free for optimal athletic performance.

5. Recognise that the body composition and training required for optimal health and performance are not identical for all athletes.

6. Screen student-athletes before the start of the season for risk factors of disordered eating using a validated screening instrument.

7. Ensure that all stakeholders (coaches, strength and conditioning coaches, athletic trainers, student-athletes, student-athlete affairs administrators and athletics department staff) are educated about the factors that put athletes at risk for disordered eating.

8. Understand your institution's referral protocol for student-athletes who are in need of assistance with nutrition or disordered eating issues.
9. Encourage help-seeking for all mental health concerns, including disordered eating.

10. Develop a plan with other stakeholders (such as university counselling services or a sports registered dietitian) for how to identify and treat student-athletes with eating disorders.

Finally, sports medicine physicians should use the preparticipation evaluation as an opportunity to educate the parents of younger athletes about disordered eating and common health consequences. Emphasising the role of nutrition in optimising performance and health is an important strategy to avoid unhealthy dietary manipulation.

\section{SUMMARY}

Eating disorders are devastating psychiatric conditions. They have an unacceptably high mortality rate and invoke considerable morbidity among those affected. Athletes are at greater risk for eating disorders given the pressure to achieve a body composition that optimises performance. While females are affected more commonly than males (at nearly a 9:1 ratio), ${ }^{12}$ both sexes are at greatest risk for eating disorder in sports where leanness confers a competitive advantage. ${ }^{12} 13$ 
Athlete medical teams need to systematically screen athletes (both male and female) as a part of the preparticipation evaluation. Once diagnosed, referral to an experienced multidisciplinary team is considered best practice. In addition to the team physician, dietitian and mental health professional, athletic trainers play a key role as the 'eyes and ears' of the healthcare team on the practice field and in the training room and oftentimes serve as the confidant and support person for the athlete who is struggling with and recovering from an eating disorder.

Sports medicine physicians play a key role in evaluation, diagnosis and treatment, including clearance and return to play. Utilising established recommendations that guide clearance and return to play decision-making can ease difficult decisions, and promote transparency and accountability in support of a healthy athlete.

Competing interests None declared.

Provenance and peer review Not commissioned; externally peer reviewed.

\section{REFERENCES}

1 Smink FR, van Hoeken D, Hoek HW. Epidemiology of eating disorders: incidence, prevalence, and mortality rates. Curr Psychiatry Rep 2012;14:406-14.

2 Keski-Rahkonen A, Hoek HW, Susser ES, et al. Epidemiology and course of anorexia nervosa in the community. Am J Psychiatry 2007;164:1259-65.

3 Fisher M. Treatment of eating disorders in children, adolescents, and young adults. Pediatr Rev 2006;27:5-16.

4 Linville $D$, Benton $A, O^{\prime} N$ eil $M$, et al. Medical providers' screening, training and intervention practices for eating disorders. Eat Disord 2010;18:110-31.

5 Hudson JI, Hiripi E, Pope HG Jr, et al. The prevalence and correlates of eating disorders in the National Comorbidity Survey Replication. Biol Psychiatry 2007;61:348-58.

6 Call C, Walsh BT, Attia E. From DSM-IV to DSM-5: changes to eating disorder diagnoses. Curr Opin Psychiatry 2013;26:532-6.

7 Johnson C, Powers PS, Dick R. Athletes and eating disorders: the National Collegiate Athletic Association study. Int J Eat Disord 1999;26:179-88.

8 Sundgot-Borgen J, Torstveit MK. Aspects of disordered eating continuum in elite high intensity sports. Scand J Med Sci Sports 2010;20(Suppl 2):112-21.

9 Thiel A, Gottfried H, Hesse FW. Subclinical eating disorders in male athletes: a study of the low weight category in rowers and wrestlers. Acta Pscyhiatr Scand 1993;88:259-65.

10 American Psychiatric Association. Diagnostic and statistical manual of mental disorders. 5th edn. Arlington, VA: American Psychiatric Association, 2013.

11 Hoek HW, van Harten PN, Hermans KM, et al. The incidence of anorexia nervosa on Curacao. Am J Psychiatry 2005;162:748-52.

12 Sundgot-Borgen J, Torstveit MK. Prevalence of eating disorders in elite athletes is higher than in the general population. Clin J Sport Med 2004;14:25-32.

13 Sundgot-Borgen J. Prevalence of eating disorders in elite female athletes. Int I Sport Nutr 1993;3:29-40.

14 Thiemann $\mathrm{P}$, Legenbauer $\mathrm{T}$, Vocks $\mathrm{S}$, et al. Eating disorders and their putative risk factors among female German professional athletes. Eur Eat Disorders Rev 2015;23:269-76.

15 Striegel RH, Silberstein LR, Frensch P, et al. A prospective study of disordered eating in college students. Int J Eat Disord 1989;8:499-509.

16 Reinking MF, Alexander LE. Prevalence of disordered-eating behaviors in undergraduate female collegiate athletes and nonathletes. J Athl Train 2005;40:47-51.

17 Glazer J. Eating disorders among male athletes. Curr Sports Med Rep 2008; $7: 332-7$

18 Kong P, Harris LM. The sporting body: body image and eating disorder symptomatology among female athletes from leanness focused and nonleanness focused sports. J Psychol 2015;149:141-60.

19 Dolan E, O'Connor H, McGoldrick A, et al. Nutritional, lifestyle, and weight control practices of professional jockeys. J Sports Sci 2011;29:791-9.

20 Fogelholm GM, Koskinen R, Laakso J, et al. Gradual and rapid weight loss: effects on nutrition and performance in male athletes. Med Sci Sports Exerc 1993;25:371-7.

21 Lingor RL, Olson A. Fluid and diet patterns associated with weight cycling and changes in body composition assessed by continuous monitoring throughout a college wrestling season. J Strength Cond Res 2010;24:1763-72.

22 Chatterton JM, Petrie TA. Prevalence of disordered eating and pathogenic weight control behaviors among male collegiate athletes. Eat Disord 2013;21:328-41.

23 Sykora C, Grilo CM, Wiffly DE, et al. Eating, weight, and dieting disturbances in male and female lightweight and heavyweight rowers. Int I Eat Disord 1993;14:203-11.

24 Rosendahl J, Bormann B, Aschenbrenner K, et al. Dieting and disordered eating in German high school athletes and nonathletes. Scand I Med Sci Sports 2009;19:731-9.
25 Steen SN, Brownell KD. Patterns of weight loss and regain in wrestlers: has the tradition changed? Med Sci Sports Exerc 1990;22:762-8.

26 Riebl SK, Subudhi AW, Broker JP, et al. The prevalence of subclinical eating disorders among male cyclists. J Am Diet Assoc 2007:107:1214-17.

27 Le Grange D, Swanson SA, Crow SJ, et al. Eating disorder not otherwise specified presentation in the US population. Int J Eat Disord 2012:45:711-18.

28 Machado PP, Gonçalves S, Hoek HW. DSM-5 reduces the proportion of EDNOS cases: evidence from community samples. Int J Eat Disord 2013;46:60-5.

29 Nakai Y, Fukushima M, Taniguchi A, et al. Comparison of DSM-IV versus proposed DSM-5 diagnostic criteria for eating disorders in a Japanese sample. Eur Eat Disord Rev 2013:21:8-14.

30 Wilson GT, Sysko R. Frequency of binge eating episodes in bulimia nervosa and binge eating disorder: diagnostic considerations. Int J Eat Disord 2009;42:603-10.

31 Meng X, D'Arcy C. Comorbidity between lifetime eating problems and mood and anxiety disorders: results from the Canadian Community Health Survey of Mental Health and Well-Being. Eur Eat Disord Rev 2015;23:156-62.

32 Rosling AM, Sparen P, Norring C, et al. Mortality of eating disorders: a follow-up study of treatment in a specialist unit 1974-2000. Int J Eat Disord 2011;44:304-10.

33 Crow SJ, Swanson SA, le Grange D, et al. Suicidal behavior in adolescents and adults with bulimia nervosa. Compr Psychiatry 2014;55:1534-9.

34 Javaras KN, Pope HG, Lalonde JK, et al. Co-occurrence of binge eating disorder with psychiatric and medical disorders. J Clin Psychiatry 2008;69:266-73.

35 Shanmugam V, Jowett S, Meyer C. Eating psychopathology as a risk factor for depressive symptoms in a sample of British athletes. I Sports Sci 2014;32:1587-95.

36 Baechle C, Stahl-Pehe A, Rosenbauer J. Disordered eating and insulin restriction in youths receiving intensified insulin treatment: results from a nationwide population-based study. Int J Eat Disord 2015. doi:10.1002/eat.22463

37 Mehler PS, Brown C. Anorexia nervosa-medical complications. J Eat Disord 2015;3:11.

38 Mehler PS, Rylander M. Bulimia nervosa-medical complications. J Eat Disord 2015;3:12.

39 Rosen DS, American Academy of Pediatrics Committee on Adolescence. Identification and management of eating disorders in children and adolescence. Pediatrics 2010;126:1240-53.

40 Harris EC, Barraclough B. Excess mortality of mental disorder. Br J Psychiatry 1998;173:11-53.

41 AED Report, 2nd Edition. Eating Disorders. 2011. http://eatingdisorders.ucsd.edu/ ed101/pdfs/AED\%20Report.pdf

42 Arcelus J, Mitchell AJ, Wales J, et al. Mortality rates in patients with anorexia nervosa and other eating disorders. A meta-analysis of 36 studies. Arch Gen Psychiatry 2011:68:724-31.

43 Crow SJ, Peterson CB, Swanson SA, et al. Increased mortality in bulimia nervosa and other eating disorders. Am J Psychiatry 2009;166:1342-6.

44 Smith $A R$, Fink EL, Anestis MD, et al. Exercise caution: over-exercise is associated with suicidality among individuals with disordered eating. Psychiatry Res 2013:206:246-55.

45 McCallum K, Bermudez O, Ohlemeyer C, et al. How should the clinician evaluate and manage the cardiovascular complications of anorexia nervosa? Eat Disord 2006;14:73-80.

46 Arcelus J, Mitchell AJ, Wales J, et al. Mortality rates in patients with anorexia nervosa and other eating disorders. Arch Gen Psychiatry 2011;68:724-31.

47 Pernick Y, Nichols JF, Rauh MJ, et al. Disordered eating among a multi-racial/ethnic sample of female high school athletes. J Adolesc Health 2006;38:689-95.

48 Colleen Stiles-Shields E, Labuschagne Z, Goldschmidt A, et al. The use of multiple methods of compensatory behaviors as an indicator for eating disorder severity in treatment-seeking youth. Int J Eat Disord 2012;45:704-10.

49 Winstead NS, Willard SG. Gastrointestinal complaints in patients with eating disorders. J Clin Gastroenterol 2006;40:678-82.

50 Intermountain Healthcare Management of Eating Disorder Care Process Model. https://intermountainhealthcare. org/ext/Dcmnt?ncid=522882792 (accessed 26 Oct 2015).

51 De Souza MJ, Nattiv A, Joy E, et al. 2014 female athlete triad coalition consensus statement on treatment and return to play of the female athlete triad: 1st International Conference held in San Francisco, California, May 2012 and 2nd International Conference held in Indianapolis, Indiana, May 2013. Br J Sports Med 2014;48:289.

52 Nattiv A, Loucks AB, Manore MM, et al. American College of sports Medicine Position Stand: the female athlete triad. Med Sci Sports Exerc 2007:39: $1867-82$

53 Tenforde A, Barrack MT, Nattiv A, et al. Parallels with the female athlete triad in male athletes. Sport Med 2015, online before print, October 2015.

54 DeSouza MJ, Miller BE. The effect of endurance training on reproductive function in male runners. A 'volume threshold' hypothesis. Sports Med 1997;23:357-74.

55 MacKelvie KJ, Taunton JE, McKay HA, et al. Bone mineral density and serum testosterone in chronically trained, high mileage $40-55$ year old male runners. Br J Sports Med 2000;34:273-8.

56 McColl EM, Wheeler GD, Gomes P, et al. The effects of acute exercise on pulsatile LH release in high-mileage male runners. Clin Endocrinol 1989;31:617-62. 
57 Hackney AC, Sinning WE, Bruot BC. Reproductive hormonal profiles of endurance-trained and untrained males. Med Sci Sports Exerc 1988;20:60-5.

58 Ackerman KE, Skrinar GS, Medvedova E, et al. Estradiol levels predict bone mineral density in male collegiate athletes: a pilot study. Clin Endocrinol (Oxf) 2012;76:339-45.

59 Hetland ML, Haarbo J, Christiansen C. Low bone mass and high bone turnover in male long distance runners. J Clin Endocrinol Metab 1993;77:770-5.

60 Hind K, Truscott JG, Evans JA. Low lumbar spine bone mineral density in both male and female endurance runners. Bone 2006:39:880-5.

61 Nattiv A, Kennedy G, Barrack MT, et al. Correlation of MRI grading of bone stress injuries with clinical risk factors and return to play a 5 -year prospective study in collegiate track and field athletes. Am J Sports Med 2013;41:1930-41.

62 Papageorgiou M, Elliott-Sale KJ, Greeves JP, et al. The effects of short-term low energy availability on bone turnover in men. Med Sci Sports Exerc 2015;46 (5Supplement):S329.

63 Smathers AM, Bemben MG, Bemben DA. Bone density comparisons in male competitive road cyclists and untrained controls. Med Sci Sports Exerc 2009;41:290-6.

64 Stewart AD, Hannan J. Total and regional bone density in male runners, cyclists and controls. Med Sci Sports Exerc 2000;32:1373-7.

65 Tenforde AS, Fredericson M, Sayres LC, et al. Identifying sex specific risk factors for low bone mineral density in adolescent runners. Am J Sports Med 2015;43:1494-504.

66 Tenforde A, Sayres LC, McCurdy ML, et al. Identifying sex specific risk factors for stress fractures in adolescent runners. Med Sci Sports Exerc 2013;45:1843-51.

67 El Ghoch M, Soave F, Calugi S, et al. Eating disorders, physical fitness and sport performance: a systematic review. Nutrients 2013;5:5140-60.

68 Vanheest JL, Rodgers CD, Mahoney CE, et al. Ovarian suppression impairs sport performance in junior elite female swimmers. Med Sci Sports Exerc 2014;46:156-66.

69 Thein-Nissenbaum JM, Rauh MJ, Carr KE, et al. Associations between disordered eating, menstrual dysfunction, and musculoskeletal injury among high school athletes. J Orthop Sports Phys Ther 2011;41:60-9.

70 Bernhardt DT, Roberts WO, American Academy of Family Physicians, American Academy of Pediatrics. PPE: preparticipation physical evaluation. 4th edn. Elk Grove Village, IL: American Academy of Pediatrics, 2010.

71 Leombruni P, Amianto F, Delsedime N, et al. Citalopram versus fluoxetine for the treatment of patients with bulimia nervosa: a single-blind randomized controlled trial. Adv Ther 2006;23:481-94.
72 Citrome L. Lisdexamfetamine for binge eating disorder in adults: a systematic review of the efficacy and safety profile for this newly approved indication-what is the number needed to treat, number needed to harm, and likelihood to be helped or harmed? Int J Clin Pract 2015;69:410-21.

73 McElroy SL, Hudson JI, Mitchell JE, et al. Efficay and safety of lisdexamfetamine for treatment of adults with moderate to severe binge-eating disorder: a randomized clinical trial. JAMA Psychiatry 2015;72:235-46.

74 Gorla K, Mathews M. Pharmacological treatment of eating disorders. Psychiatry (Edgmont) 2005;2:43-8.

75 Kishi T, Kafantaris V, Sunday $\mathrm{S}$, et al. Are antipsychotics effective for the treatment of anorexia nervosa? Results from a systematic review and meta-analysis. J Clin Psychiatry 2012;73:e757-66.

76 American Psychiatric Association (APA). Practice guideline for the treatment of patients with eating disorders. 3rd edn. 2006. http://psychiatryonline.org/pdfaccess. ashx? ResourcelD $=243187 \&$ PDFSource $=6$

77 Mehler PS, Krantz MJ, Sachs KV. Treatment of medical complications of anorexia nervosa and bulimia nervosa. J Eat Disord 2015;3:15.

78 Mountjoy M, Sundgot-Borgen J, Burke L, et al. The IOC consensus statement: beyond the Female Athlete Triad-Relative Energy Deficiency in Sport (RED-S). Br J Sports Med 2014;48:491-7.

79 Coelho GM, Gomes Al, Ribeiro BG, et al. Prevention of eating disorders in female athletes. Open Access J Sports Med 2014;5:105-13.

80 Becker CB, McDaniel L, Bull S, et al. Can we reduce eating disorder risk factors in female college athletes? A randomized exploratory investigation of two peer-led interventions. Body Image 2012;9:31-42.

81 Martinsen M, Sherman RT, Thompson RA, et al. Coaches' knowledge and management of eating disorders: a randomized controlled trial. Med Sci Sports Exerc 2015;47:1070-8.

82 NCAA Resources Related to Disordered Eating. 23 Febuary 2015. http://www.ncaa. org/health-and-safety/sport-science-institute/ncaa-resources-related-disordered-eating (accessed 25 Oct 2015).

83 Kroshus E. "10 Eating Disorders Awareness Tips for Coaches and Athletics Professionals." 23 Febuary 2015. http://www.ncaa.org/health-and-safety/ sport-science-institute/10-eating-disorders-awareness-tips-coaches-and-athleticsprofessionals (accessed 25 Oct 2015). 